\title{
Short Term Clinical and Angiographic Outcome of Skeletonized Harvesting Technique of Left Internal Mammary Artery, Compared to Pedicled Harvesting for Coronary Revascularization
}

\author{
MD FAIZUS SAZZAD ${ }^{1}$, MOHAMMAD MONIRUZZAMAN ${ }^{2}$, PRASANTA KUMAR CHANDA ${ }^{3}$, \\ MIR NESAR UDDIN AHMED ${ }^{3}$, HAROON RASHEED ${ }^{3}$, NOYEL CYPRIAN GOMEZ ${ }^{3}$, MD. SHAUKAT ALI ${ }^{4}$, \\ SOHEL REZA CHOUDHURY ${ }^{5}$, FAZILA-TUN-NESA MALIK ${ }^{6}$, FAROOQUE AHMED ${ }^{3}$ \\ ${ }^{1}$ Department of Cardiac Surgery, Ibrahim Cardiac Hospital \& Research Institute, Dhaka, ${ }^{2}$ Department of Cardiac Surgery, ZH \\ Sikder Women's Medical College \& Hospital, Dhaka, ${ }^{3}$ Department of Cardiac Surgery, National Heart Foundation Hospital \& \\ Research Institute, Dhaka, ${ }^{4}$ Department of Cardiac Surgery, Bangladesh Specialized Hospital, Dhaka, ${ }^{5}$ Department of Epidemiology, \\ National Heart Foundation Hospital \& Research Institute, Dhaka, ${ }^{6}$ Department of Cardiology, National Heart Foundation Hospital \& \\ Research Institute, Dhaka
}

Address of Correspondence: Dr. Md Faizus Sazzad, Associate Consultant, Department of Cardiac Surgery Ibrahim Cardiac Hospital \& Research Institute, Dhaka.Email: mfsazzad@gmail.com

\begin{abstract}
We examined the hypothesis that the short term clinical and angiographic outcome of skeletonized Left Internal Mammary Artery (LIMA) is better than that of pedicled LIMA used for revascularization of left anterior descending artery at CABG surgery at the Department of Cardiac Surgery, National Heart Foundation Hospital and Research Institute from May 2011 to April 2012. Accordingly we studied 60 consecutive patients who underwent coronary artery bypass grafting, in which the LIMA was anastomosed to the left anterior descending artery (LAD). In 30 consecutive LIMAs were harvested as a pedicle (Control Group) and another 30 consecutive LIMAs were harvested as skeletonized graft (Experimental Group). Three diameters of the LIMA graft were measured quantitatively in postoperative angiograms performed 6 \pm 1 month after the coronary artery bypass grafting; D1, at the origin from the subclavian artery; D2, at the level of the second intercostal space; and D3, just proximal to the anastomosis. Our study shows that, complete skeletonization results in increased graft length $19.71 \pm 1.77 \mathrm{~cm}$ in skeletonized group vs. 17.08 $\pm 0.71 \mathrm{~cm}$ in pedicle group $(p<0.001)$. Although there was similar incidence of superûcial wound complications between the groups, the post CABG pain (PCP) was significantly higher in pedicled group at the 6 month follow-up. Check coronary angiography showed the LIMA grafts to the LAD were all patent. There was increased diameter achievement in skeletonized group at the anastomotic site (D3: $1.78 \pm 0.21 \mathrm{~mm} v \mathrm{vs} .66$ $\pm 0.18 \mathrm{~mm} ; \boldsymbol{p}=0.03)$. We conclude that skeletonized LIMA showed a better functional behavior, giving longer conduit length and superior postoperative clinical and angiographic profile.
\end{abstract}

Key Words: Skeletonization of IMA, Coronary artery bypass.

Introduction:

Bypass graft patency is an important factor to predict patient outcome after CABG and the unsatisfactory longterm result of vein grafts have led to an increased use of arterial grafts. The Internal mammary artery (IMA) offers patient survival benefit and superior graft patency compared with vein grafts. ${ }^{1}$ Arterial conduits are very rarely inferior to vein grafts in achieving better patency and improved long-term results. For this reason, at least one arterial graft, usually the LIMA to the LAD, is attempted in virtually every patient undergoing coronary revascu-larization.

LIMA has been considered as the gold standard conduit choice for grafting the left anterior descending coronary artery for myocardial revascularization. ${ }^{2}$ Given its longterm survival benefit, surgeons must harvest the LIMA in the best possible way to achieve both short-term and long-term advantages. Despite the popularity of the LIMA, however, it is still debated whether to use it as a pedicled graft or as a skeletonized graft.

However, the literature has often reported some advantages of the skeletonized LIMA over the pedicled conduit, ranging from the achievement of a longer conduit ${ }^{3,4}$, to a higher free flow, ${ }^{5-7}$ to the reduced risk of sternal wound complications. ${ }^{8,9}$ Mobilizing the internal mammary artery as a skeletonized graft rather than a full thickness pedicle, tends to better preserve the integrity of the inner chest wall, preserve collateral sternal vascular bed and perfusion and decrease the rate of postoperative sternotomy related complications. ${ }^{9}$ It is postulated that the skeletonization technique of LIMA harvesting would also reduce the incidence of post CABG pain (PCP). 
Most current knowledge on this subject is supported primarily by observational studies that offer insufficient evidence for or against each harvesting technique. ${ }^{10}$ The randomized studied comparing the skeletonized to pedicled LIMA are few and focused only on sternal perfusion, ${ }^{11,12}$ vessel wall integrity ${ }^{13}$ and vasoreactive profiles. ${ }^{14}$ Major limitations of these studied are the small sample size that may lead to unbalanced distribution of confounders, the limited relevance of the end points studied, the lack of postoperative LIMA flow evaluation, and angiographic assessment.

Despite a number of studies that have addressed the superiority of the skeletonized LIMA, little is known about the in-vivo functional behavior of skeletonized and pedicled grafts. Although the survival advantage of LIMAs compared with other grafts is accepted worldwide, no clear benifits of one harvesting technique over the other have been definitely demonstrated.

The present study is designed to see the short-term clinical outcomes of skeletonized and pedicled techniques used in harvesting the LIMA for coronary revascularization. As the coronary angiography still remains the gold standard investigation for coronary evaluation, therefore the aim of this study is to find out the analysis of angiographic results in our settings.

\section{Materials \& Methods}

The present study evaluates clinical and angiographic results of a prospective series of patients undergoing coronary artery bypass graft surgery (CABG) with pedicled LIMA (Control group) or skeletonized LIMA (Experimental group), performed either off pump (OPCABG) or on pump, at a single academic institution. The study protocol was approved by the institution's Ethical Committee/Institutional Review Board, and informed consent was obtained. The decision for a patient to have a graft in LAD by using whether a pedicled or skeletonized LIMA was decided by the operating surgeon. Additional cardiac or vascular surgical procedures and severe systemic comorbidities (Renal failure, hepatic failure, cancer, autoimmune disease) were the exclusion criteria. Because the different geometry for the construction of a $\mathrm{Y}$ graft or $\mathrm{T}$ graft inûuenced angiographic results, coronary revascularization with these grafts were excluded from the analysis.

\section{Surgical Technique:}

All surgical procedures were performed by the same surgical team. In all patients, CABG was performed through a median sternotomy, and the left anterior descending artery was always grafted using the LIMA. The pedicled LIMA (Figure-1) was harvested together with the surrounding veins, muscle, and fascia. Low-voltage (10-20 mV) cautery always used and the side branches were clipped. In both groups, the LIMA was harvested from the bifurcation of the musculophrenic and superior epigastric arteries up to the upper margin of the first rib. The width of pedicled LIMAs ranged from 1 to $1.5 \mathrm{~cm}$. To avoid any distortion to the graft, the pedicle was secured with two epicardial stitches using 6-0 polypropylene on both sides after completion of distal anastomosis.

The Skeletonization technique was as follows. After having dissected the reflection of the mediastinal pleura from the endothoracic fascia, the mammary artery and both satellite veins were visualized. The fascia was incised medially to the medial mammary vein for the whole length of the vessel, and pulled down on the pleura. A blunt dissection of the artery from the chest wall was performed by means of low-voltage $(10 \mathrm{mV})$ cautery or cold tip; the sternal and the anterior intercostal branches were occluded with hemoclips. Collaterals were divided using low voltage cautery, and its mammary side similarly was occluded with small haemostatic clips (Figure-2).

Both pedicled and skeletonized LIMAs were at the distal end proximal to bifurcation, and checked for a good pulsatile free flow $(>50 \mathrm{ml} / \mathrm{min}$ ) before their use. No vasodilators or other drug was injected inside the LIMA at any time (intraluminal no-touch technique). Distal anastomosis was constructed using 8-0 polypropylene sutures.

Three stitches were made around the "heel" of the graft: One stitch on one side of the apex of the graft, one stitch through the apex, and one stitch on the opposite side. Until the stitches in place, the graft was not connected to the coronary artery. The suture loops were pulled up to approximate the graft to the coronary artery. The anstomosis was completed by placing stitches around the toe of the graft in a clockwise direction. Exposure and stabilization was achieved with the Acrobat ${ }^{\mathrm{TM}}$ Vaccum off pump system (Guidant) and intra-coronary shunts were used routinely. No Apical-suction device was used in whole series.

\section{Check Angiogram:}

A check angiogram was done $6 \pm 1$ month post-operatively. The three points for diameter measurements on the postoperative quantitative angiogram of the left internal mammary artery (LIMA) graft was done by using an automatic edge-detection program calibrated with the diameter of the catheter used (Figure-3): D1, at the origin 
from the left subclavian artery; D2, at the level of the second intercostal space; and D3, just proximal to the anastomosis. The diameter of the left anterior descending artery (LAD) was also measured just distal to the anastomosis with the internal mammary artery (D4). Post-operative coronary angiography of each patient was reviewed by two cardiologists, blinded toward the study.

\section{Results:}

Clinical Outcome and Complications

Table-1 showing the preoperative variables and operative data. Time required for harvesting the LIMA was significantly less in Control Group than that in Experimental Group (40.73 \pm 5.93 min vs. $23.53 \pm 3.13$ $\min , \mathrm{p}<0.001)$. LIMA flow was comparable between two groups $98.33 \pm 20.81 \mathrm{ml} / \mathrm{min}$ vs. $92 \pm 15.62 \mathrm{ml} / \mathrm{min}$ $(p=0.18)$. There was significant difference in length of LIMA in two groups. Experimental Group had significantly higher length than that of Control Group (19.71 \pm 1.77 cm vs. $17.08 \pm 0.71 \mathrm{~cm}, \mathrm{p}<0.001) .16 .66 \%$ of patient in both group complained of superficial sternal wound infection after surgery, which was also statistically non significant $(\mathrm{p}=0.34)$. None of both groups were having any deep sternal wound infection at any time. $53.33 \%$ of patient in Experimental Group were complaining of post CABG pain (PCP) compared to $70 \%$ of Control Group in hospital days after surgery $(p=0.18)$. At $1^{\text {st }}$ follow-up (30 days) the PCP reduced to $36.77 \%$ for Experimental Group and 53.33\% for Control Group with non significant statistical difference $(p=0.19)$. In $2^{\text {nd }}$ follow up (3months) the PCP was 10\% in Experimental Group, which was similar $17.24 \%$ in Control Group $(p=0.33)$. There was significant PCP in Control Group at 6 month follow up ( $3^{\text {rd }}$ follow up) compared to Experimental Group $(p<0.05)$. There was no operative death in either group. One patient in control group died during follow-up.

\section{Postoperative Quantitative Angiography}

The IMA grafts to the LAD were all patent (Table-2). There was no significant difference in D1, D2 or D4 in either group $(p=0.84, p=0.90$ and $p=0.29$ respectively). D3 was greater in Experimental Group than in Control Group $(1.78 \pm 0.21$ vs. $1.66 \pm 0.18 \mathrm{~mm}, \mathrm{p}=$ $0.03)$. The ratio $\mathrm{D} 3 / \mathrm{D} 1$, which implies the degree of narrowing along the LIMA graft, was greater in Experimental Group than in Control Group $(0.80 \pm 0.05$ vs. $0.76 \pm 0.07, \mathrm{p}=0.02$ )

Table-I

Preoperative and Intraoperative Data

\begin{tabular}{|c|c|c|c|}
\hline \multirow[t]{2}{*}{ Variables } & \multicolumn{2}{|c|}{ Group } & \multirow{2}{*}{$\begin{array}{c}\mathrm{p}- \\
\text { value }\end{array}$} \\
\hline & $\begin{array}{l}\text { Experimental Group } \\
(\mathrm{n}=30)\end{array}$ & $\begin{array}{l}\text { Control Group } \\
(\mathrm{n}=30)\end{array}$ & \\
\hline Age (yrs) & $53.37 \pm 6.66$ & $52.80 \pm 7.76$ & $0.76^{\mathrm{NS}}$ \\
\hline Male/Female & $25 / 5$ & $26 / 4$ & $0.50^{\mathrm{NS}}$ \\
\hline Body Mass Index $\left(\mathrm{kg} / \mathrm{m}^{2}\right)$ & $24.15 \pm 2.77$ & $23.53 \pm 3.13$ & $0.417^{\mathrm{NS}}$ \\
\hline Body surface area(sq. m) & $1.68 \pm 0.13$ & $1.67 \pm 0.14$ & $0.68^{\mathrm{NS}}$ \\
\hline Obesity & $9(30)$ & $5(16.67)$ & $0.22^{\mathrm{NS}}$ \\
\hline Hypertension & $18(60)$ & $17(56.67)$ & $0.79^{\mathrm{NS}}$ \\
\hline Diabetes Mellitus & $15(50) 13(43.33)$ & $0.60^{\mathrm{NS}}$ & \\
\hline Dyslipidemia & $3(10)$ & $15(50)$ & $0.001^{\mathrm{S}}$ \\
\hline Unstable Angina & $8(26.77)$ & $3(10)$ & $0.09^{\mathrm{NS}}$ \\
\hline Cerebrovascular disease & $1(3.33)$ & $1(3.33)$ & $0.75^{\mathrm{NS}}$ \\
\hline Congestive Heart Failure & $1(3.33)$ & $1(3.33)$ & $0.75^{\mathrm{NS}}$ \\
\hline Pre-operative arrhythmia & $2(6.77)$ & $2(6.77)$ & $0.69^{\mathrm{NS}}$ \\
\hline Carotid artery disease & $1(3.33)$ & $0(0)$ & $0.50^{\mathrm{NS}}$ \\
\hline $\operatorname{LVEF}(\%)$ & $53.83 \pm 8.14$ & $55.70 \pm 8.64$ & $0.39^{\mathrm{NS}}$ \\
\hline Left main disease & $7(23.33)$ & $2(6.67)$ & $0.07 \mathrm{NS}$ \\
\hline Duration of operation(min) & $317.01 \pm 46.61$ & $307 \pm 40.44$ & $0.37^{\mathrm{NS}}$ \\
\hline CPB used & $3(10)$ & $1(3.3)$ & $0.30^{\mathrm{NS}}$ \\
\hline Number of anastomosis/pt & $3.63 \pm 0.80$ & $3.87 \pm 0.90$ & $0.295^{\mathrm{NS}}$ \\
\hline Mechanical ventilation time (min) & $633.83 \pm 206.01$ & $770.33 \pm 544.17$ & $0.20^{\mathrm{NS}}$ \\
\hline Duration of ICU stay (hrs) & $61.5 \pm 11.31$ & $62.23 \pm 21.77$ & $0.87^{\mathrm{NS}}$ \\
\hline Hospital stay (days) & $8 \pm 1.17$ & $8.53 \pm 3.79$ & $0.46^{\mathrm{NS}}$ \\
\hline Blood loss (ml) & $485.33 \pm 220.74$ & $466.50 \pm 284.96$ & $0.77^{\mathrm{NS}}$ \\
\hline
\end{tabular}

$\mathrm{LVEF}=\mathrm{Left}$ ventricular ejection fraction, $\mathrm{CPB}=$ Cardio-pulmonary bypass, $\mathrm{ICU}=$ Intensive care unit. 


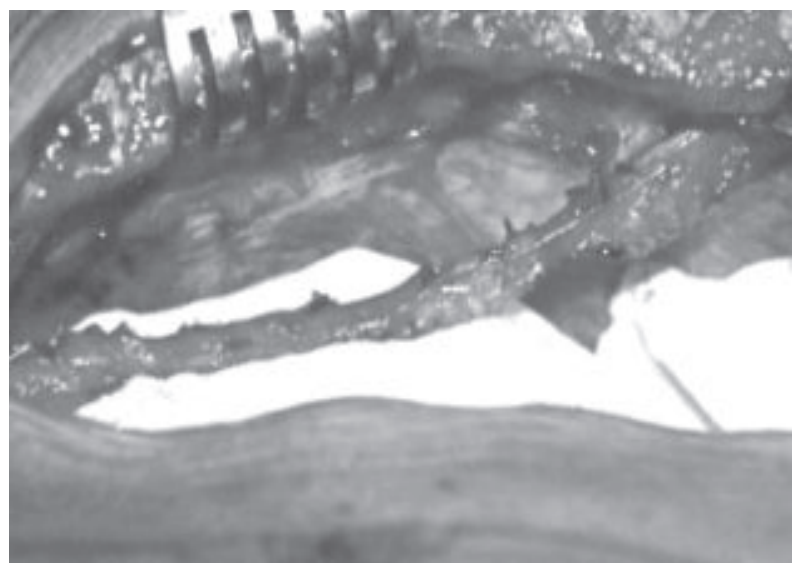

Fig.-1: Harvested pedicled Left internal mammary artery using IMA retractor system

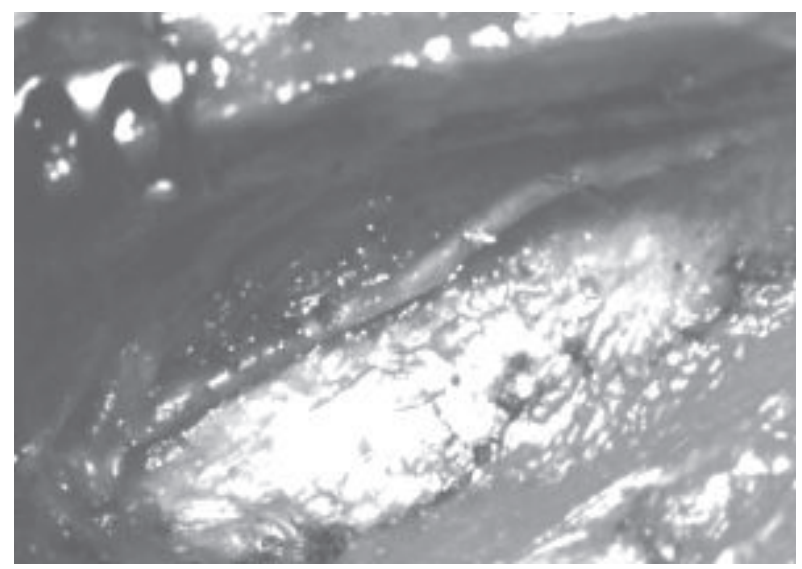

Fig.-2: Harvested Skeletonized Left internal mammary artery using IMA retractor system

\section{Discussion:}

The present study showed, complete skeletonization with a blunt dissection of the artery from the chest wall by means of low-voltage $(10 \mathrm{mV})$ cautery or cold tip, results in increased graft length of skeletonized LIMA; similar to Calafiore and colleagues. ${ }^{15}$ Time required for harvesting was significantly less for pedicled LIMA; similar significant result given by Kamiya et al but harvesting time was almost half in both groups than that in our study. ${ }^{12}$

It has to be kept in mind that very few studies have evaluated the functional behavior of the conduits and its usability in the operation theater, most focusing on the free-ûow capacity. Both Deja and coworkers ${ }^{16}$ and Wendler and coworkers ${ }^{6}$ found skeletonized LIMAs to have higher free ûow compared with pedicled conduits, but we found LIMA flow was similar between two groups.

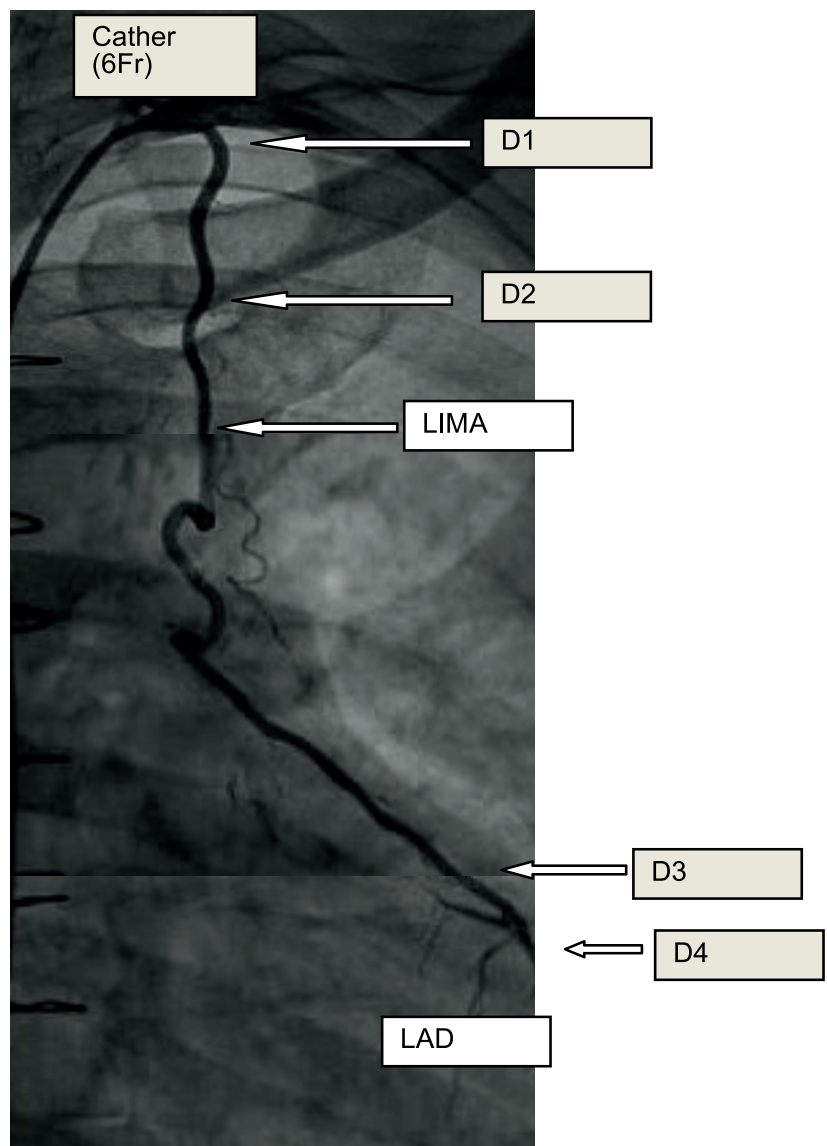

Fig.-3: The three points for diameter measurements on the postoperative quantitative angiogram of the LIMA graft.D1, at the origin from the left subclavian artery; D2, at the level of the second intercostal space; and D3, just proximal to the anastomosis. D4, the diameter of LAD just distal to the anastomosis.

Both studies measured ûows after intra-arterial papaverine injection, which has been demonstrated to cause endothelial damage to the mammary artery by Noera et al. ${ }^{17}$ Accordingly, we never used intraluminal papaverine on LIMA.

Furthermore, Wendler and coworkers ${ }^{6}$ analyzed only a limited number of grafts, initially showing comparable pedicled and skeletonized graft free ûows. These studies did not report if differences existed between the two techniques in the caliber of LIMA, which seems to be the most important factor for free ûow measurements. However, surgeons now have the possibility of studying the functional "in-vivo" behavior of the grafts, after completion of distal anastomoses, through the aid of TTF (Transit time flowmetry) technology.

We found a similar incidence of superûcial wound complications in patients undergoing skeletonized LIMA 
harvesting compared with the pedicle group with no case of deep sternal wound infection. It can be argued that the relatively low incidence of such complication in our practice may explain such discrepancy. Moreover, it can be hypothesized that the relatively small width of the pedicle $(1$ to $1.5 \mathrm{~cm})$ mammary grafting in the study period may further account for these results. However, a recent review by Athanasiou and coworkers ${ }^{18}$ showed that the only evidence from the current literature is a higher sternal devascularization with the pedicled technique.

In our study we compared to chest pain within 6 months after surgery, the result showed significant PCP in Control Group at 6 month follow up compared to Experimental Group $(\mathrm{p}<0.05)$. Yaron et $\mathrm{al}^{19}$ showed the incidence of PCP was similar in pedicle or skeletonized mammary artery group.

Our study showed complete LIMA skeletonization results in increased graft diameter for the anastomosis measured by quantitative coronary angiography with an edge detection algorithm. Currently, it has an established role in coronary intervention and post-CABG assessment. ${ }^{20} \mathrm{We}$ could obtain the LIMA diameter measurements more precisely by this modality than in the previous reports. 5,6 The beneûts of LIMA skeletonization are an anastomosis with a larger diameter and decrease in graft vascular resistance; these factors may prevent the hypoperfusion syndrome in $\mathrm{CABG}$ using LIMA. This syndrome is a rare but life-threatening perioperative clinical syndrome manifested by low cardiac output, left ventricular failure, and cardiac arrest. ${ }^{21}$ The major contributory factor to hypoperfusion is a disproportion between LIMA ûow and myocardial demand because of the small LIMA size, overzealous use of sequential grafting, and severe left ventricular hypertrophy. Considering the current wide use of LIMA, including sequential and bilateral, LIMA skeletonization may be an efûcient strategy to prevent perioperative hypoperfusion syndrome, especially in offpump CABG without assisted circulation. To increase the LIMA graft ûow it is necessary to increase the diameter at the anastomosis by the complete skeletonization. We believe that LIMA skeletonization may add perioperative beneûts to the long term excellent clinical results, which has already been achieved by many surgeons using pedicled LIMA. The results of this study and discussion thereof prompt us to recommend that skeletonized harvesting is better when compared to pedicled.

\section{Limitations of the study}

The study has been prospectively designed, but no real randomization has been performed, although such a goal may be very difficult to reach in current clinical practice. Different and complex mechanisms affect graft patency during follow-up, first of all the progression of atherosclerosis and co-morbid conditions. It can therefore be a mistake to only attribute graft patency to a single surgical variable, such as the harvesting technique. Finally, this is a single-center study, which does not guarantee uniformity of the perioperative management of the patient population.

\section{References:}

1. Cunningham JM, Gharavi MA, Fardin R, and Meek RA. Considerations in the skeletonization technique of internal thoracic artery dissection. Ann Thorac Surg 1992; 54:947-951.

2. Karthik S, Srinivasan AK, Grayson AD, Jackson M, and Mediratta NK. Left internal mammary artery to the left anterior descending artery: effect on morbidity and mortality and reasons for nonusage. Ann Thorac Surg 2004; 78:142-148.

3. Keeley SB. The skeletonized internal mammary artery. Ann Thorac Surg 1987; 44:324-325.

4. Adhikary AB, Chanda PK, Ahamed NU, Rahman MM, Shaha SK, Roy J et al. Skelitonization of LIMA/RIMA- Early experiences of 270 cases. Bangladesh Heart Journal 2004; 19(2): 120-121.

5. Choi JB, and Lee SY. Skeletonized and pedicled internal thoracic artery grafts: effect on free flow during bypass. Ann Thorac Surg 1996; 61:909-913.

6. Wendler O, Tscholl D, Huang Q and Schäfers HJ. Free ûow capacity of skeletonized versus pedicled internal thoracic artery grafts in coronary artery bypass grafts. Eur J Cardio- thorac Surg 1999; 15:247-50.

7. Walpoth BH, Monadjer A, Gersbach P, Rogulenko R, Walpoth BN and Althaus U. Intraoperative internal mammary artery transit-ûow measurements: comparative evaluation of two surgical pedicle preparation techniques. Eur J Cardio thorac Surg 1996; 10:1064 1070.

8. Cohen AJ, Lockman J, Lorberboym M, Bder O, Cohen N, Medalion B et al. Assessment of sternal vascularity with single photon emission tomography after harvesting of the internal thoracic artery. J Thorac Cardiovasc Surg 1999; 118:496-502.

9. Saso S, James D, vecht JA, Kidher E, Kokotsakis J, Malinovski V et al. Effect of skeletonization of the internal thoracic artery for coronary revascularization on the incidence of sternal wound infection. Ann Thorac Surg; 2010; 89:661-670.

10. Mannacio V, Tommaso LD, Amicis VD, Stassano P, and Vosa C. Randomized flow capacity comparison of skeletonized and pedicled left internal mammary artery. Ann Thorac Surg; 2011; 91:24 -30.

11. Boodhwani M, Lam K, Nathan HJ, Mesana TG, Ruel M, Zeng W et al. Skeletonized internal thoracic artery harvest reduces pain and dysesthesia and improves sternal perfusion after coronary artery bypass surgery a randomized, double-blind, within-patient comparison. Circulation; 2006, 114:766-773.

12. Kamiya H, Akhyari P, Martens A, karck M, haverich A and Lichtenberg A. Sternal microcirculation after skeletonized versus 
pedicled harvesting of the internal thoracic artery: A randomized study. J Thorac Cardiovasc Surg 2008; 135:32-37.

13. Gaudino M, Toesca A, Nori SL, Glieca F, and Possati G. Effect of skeletonization of the internal thoracic artery on vessel wall integrity. Ann Thorac Surg; 1999; 68:1623-1627.

14. Gaudino M, Toesca A, Glieca F, Girola F, Luciani N, and Possati G. Skeletonization does not influence internal thoracic artery innervation. Ann Thorac Surg 2004;77:1257-1261.

15. Calafiore AM, Vitolla G, Iaco AL, Fino C, Giammarco GD, Marchesani $\mathrm{F}$ et al. Bilateral internal mammary artery grafting: midterm results of pedicled versus skeletonized conduits. Ann Thorac Surg 1999; 67:1637-1642.

16. Deja MA, Wos S, Golba KS, Zurek P, Domaradzki W, Bachowski R et al. Intraoperative and laboratory evaluation of skeletonized versus pedicled internal thoracic artery. Ann Thorac Surg 1999; 68:2164-2168.
17. Noera G, Pensa P, Lodi R, Lammara M, Biagi B and Guelû P. Inûuence of different harvesting techniques on the arterial wall of the internal mammary artery graft: microscopic analysis. Thorac Cardiovasc Surg 1993; 41:16-20.

18. Athanasiou T, Crossman MC, Asimakopoulos G, Cherian A, Weerasinghe A, Glenville B et al. Should the internal thoracic artery be skeletonized? Ann Thorac Surg 2004; 77:2238-46.

19. Yaron BE, Gilboaa B, Unger N, Pudc D and Eisenberga E. Skeletonized versus pedicled internal mammary artery: impact of surgical technique on post CABG surgery pain. Euro J Cardiothoracic Surg 2005; 27:1065-1069.

20. Poirier NC, Carrier M, Lespérance J, Côté G, Pellerin M, Perrault LP et al. Quantitative angiographic assessment of coronary anastomoses performed without cardiopulmonary bypass. J Thorac Cardiovasc Surg 1999; 117:292- 297.

21. Loop F, Thomas J. Hypoperfusion after arterial bypass grafting. Ann Thorac Surg 1993; 56:812-3. 